Research Article

\title{
Evaluating the Dependence between Temperature and Precipitation to Better Estimate the Risks of Concurrent Extreme Weather Events
}

\author{
Hussein Wazneh $\mathbb{D}^{1,2,3}$ M. Altaf Arain ${ }^{1 D},{ }^{1}$ Paulin Coulibaly $\mathbb{I D}^{1,4}$ and Philippe Gachon ${ }^{10}{ }^{2,3}$ \\ ${ }^{1}$ School of Geography and Earth Sciences and McMaster Centre for Climate Change, McMaster University, 1280 Main St. West, \\ Hamilton, ON L8S4K8, Canada \\ ${ }^{2}$ Department of Earth and Atmospheric Sciences, University of Québec at Montréal (UQAM), Québec, Canada \\ ${ }^{3}$ ESCER (Étude et Simulation du Climat à l'Échelle Régionale) Centre, University of Québec at Montréal (UQAM), \\ Québec, Canada \\ ${ }^{4}$ Department of Civil Engineering, McMaster University, 1280 Main St. West, Hamilton, ON L8S4K8, Canada
}

Correspondence should be addressed to Hussein Wazneh; wazneh.hussein@uqam.ca

Received 7 January 2020; Revised 17 September 2020; Accepted 30 October 2020; Published 17 November 2020

Academic Editor: Tomeu Rigo

Copyright (c) 2020 Hussein Wazneh et al. This is an open access article distributed under the Creative Commons Attribution License, which permits unrestricted use, distribution, and reproduction in any medium, provided the original work is properly cited.

\begin{abstract}
Precipitation and temperature are among major climatic variables that are used to characterize extreme weather events, which can have profound impacts on ecosystems and society. Accurate simulation of these variables at the local scale is essential to adapt urban systems and policies to future climatic changes. However, accurate simulation of these climatic variables is difficult due to possible interdependence and feedbacks among them. In this paper, the concept of copulas was used to model seasonal interdependence between precipitation and temperature. Five copula functions were fitted to grid (approximately $10 \mathrm{~km} \times 10 \mathrm{~km}$ ) climate data from 1960 to 2013 in southern Ontario, Canada. Theoretical and empirical copulas were then compared with each other to select the most appropriate copula family for this region. Results showed that, of the tested copulas, none of them consistently performed the best over the entire region during all seasons. However, Gumbel copula was the best performer during the winter season, and Clayton performed best in the summer. More variability in terms of best copula was found in spring and fall seasons. By examining the likelihoods of concurrent extreme temperature and precipitation periods including wet/cool in the winter and dry/hot in the summer, we found that ignoring the joint distribution and confounding impacts of precipitation and temperature lead to the underestimation of occurrence of probabilities for these two concurrent extreme modes. This underestimation can also lead to incorrect conclusions and flawed decisions in terms of the severity of these extreme events.
\end{abstract}

\section{Introduction}

Extreme weather events can have serious physical and economic impacts on urban and rural communities [1-3]. According to the Fifth Assessment Report of the Intergovernmental Panel on Climate Change [4], warm temperature extremes are expected to increase and cold temperature extremes are projected to decline over the next several decades [5]. Additionally, significant increases in extreme precipitation events have been projected to occur in many areas over the 21 st century but with strong variability across the years [6]. Estrella and Menzel [7] found that interdependence of climate variables may have a more severe influence on spatial climate change rather than the influence of any single climate variable, for example, the combined effects on both temperature and precipitation changes on drought occurrence and severity over the Canadian Prairies [8]. Other studies have also assessed the dependence between climate variables and extreme events. AghaKouchak et al. [9] found that the impacts of drought and heat events in the United States significantly increased when they occurred concurrently. Little et al. [10] found that sea-level rise and 
changes in the frequency and intensity of tropical cyclones will increase flooding risk in the future in the East Coast of the United States.

Most climate change impact studies consider variations in temperature and precipitation independently. However, these two variables are physically dependent through several mechanisms. For example, rainfall influences soil moisture, which in turn may have an impact on the surface and lowlevel air temperature through the effects of diabatic fluxes and partition between sensible and latent heat fluxes or lower/higher Bowen ratio [11, 12]. The interaction of extreme temperature and precipitation may lead to high impact weather events and associated natural disasters with significant consequence on agriculture and other sectors of the economy [13]. For example, a drought accompanying heat wave can affect water availability for food production $[14,15]$ as well as drinking water resources. In addition, temperature-precipitation interdependence in models may influence snow cover distribution and duration simulations $[16,17]$, as well as flood occurrences and duration in spring over many regions particularly in Canada [18]. As a result, attention should be directed towards the combined effects of temperature and precipitation changes and their confounding impacts. Recent analyses of the dependence between temperature and precipitation are becoming a focus of meteorology and disaster prevention reduction research $[19,20]$.

Many studies have shown that links between temperature and precipitation vary spatially and seasonally [21-24]. Johns et al. [25] used scatter diagrams of annual mean precipitation and temperature anomalies to show a global linear correlation which was simulated by most climate models for the period of 1980-1990. Based on the HadGEM2 model, Caesar and Lowe [26] analyzed the correlation between average annual temperature and extreme precipitation. They found a proportionally high correlation between the two. Dai et al. [27] found a strong negative correlation between precipitation, maximum temperature (Tmax), and diurnal temperature range at short timescales during the warm season globally. A negative correlation between summer precipitation and temperature was found for most of the continental United States, which indicates that warm summers tend to be dryer and colder summers tend to be wetter [24]. In Canada, the temperature-precipitation interdependence tends to increase with latitude and is particularly strong in the Northwest Territories and relatively weak in the Prairies [21], but these correlation patterns vary between winter and summer months [28]. Southeastern Ontario and Quebec show almost no dependence of precipitation upon temperature during the summer (e.g., July), but there is a general negative correlation between monthly mean anomalies of temperature and precipitation for groups of months occurring over the period of May/June/July/ August/September [28]. In general, less/more precipitation falls during warm summer/winters months. In the eastern Rockies region, Isaac and Stuart [21] found that more precipitation occurs when the temperature is generally colder, regardless of season, as shown also in the study of Trenbeth and Shea [28]. This can be due to regular low- pressure systems (i.e., presence of the Alberta Clippers) moving from the west towards the Alberta area.

Most studies that analyze the dependence between temperature and precipitation have assumed a linear relationship and a normal distribution of both variables (e.g., $[21,24,28])$. Therefore, the related results are likely to be inaccurate if one or both variables fail to satisfy the normal distribution condition, especially as precipitation is not normally distributed as well as low-level air temperatures for winter months due to nonlinear feedbacks induced by the presence of snow on the ground. Additionally, the linear correlation ignores high peak fluctuation and dependence structure [29]. In this study, we apply a copula-based approach to analyze the significance of the interdependence relationship between precipitation and temperature to overcome the issue of normality undistributed data. The interdependence of precipitation and temperature using copula has not been extensively investigated in the literature, especially for southern Ontario [11,30]. Cong and Brady [11] used copulas to study the dependence between temperature and rainfall for Scania (Sweden's southernmost province). They found a significant negative correlation from April to September. In terms of copula, Student was selected as more appropriate for this region. They stated that their results are strongly related to the studied region, and those results vary spatially (from region to region) and temporally. In this study, a copula-based approach was used to determine the inherent relationship between daily mean temperature and total precipitation (precipitation $>0.1 \mathrm{~mm}$ ). Five copula functions belonging to three different families were constructed to identify the joint distribution or interdependence of precipitation and temperature (see the following section). The proposed approach was applied to gridded $(0.0833$ degrees or $\sim 10 \mathrm{~km} \times 10 \mathrm{~km})$ climate data available over the whole Canada but was used for a specific region in southern Ontario, Canada. This study is the first that focuses on the examination and quantification of the nonlinear dependence between precipitation and temperature using copulas in southern Ontario.

\section{Methods}

2.1. Study Region and Datasets. The study region is located in southern Ontario, Canada (Figure 1). The study area is located between $42^{\circ} 18^{\prime} \mathrm{N} 83^{\circ} 01^{\prime} \mathrm{W}$ and $45^{\circ} 31^{\prime} \mathrm{N} 74^{\circ} 06^{\prime} \mathrm{W}$ and bounded on the south by the international border with the United States. The region encloses approximately $100,000 \mathrm{~km}^{2}$. This region is home to about 11 million people (2016 Census of Canada) and represents almost one-third of Canada's population and approximately $75 \%$ of the province of Ontario's population. The climate in eastern Canada, including the study area, is partly influenced by topographical effects, the Niagara Escarpment, and large lakes [31]. The Niagara Escarpment crosses the study area from Georgian Bay in the northwest to Lake Erie in the east and influences rainfall patterns in the region. In addition, the Laurentian Great Lakes have major effects on the climate in the region including the following: (1) the moderation of extreme temperatures in all seasons, (2) an increase in cloud 


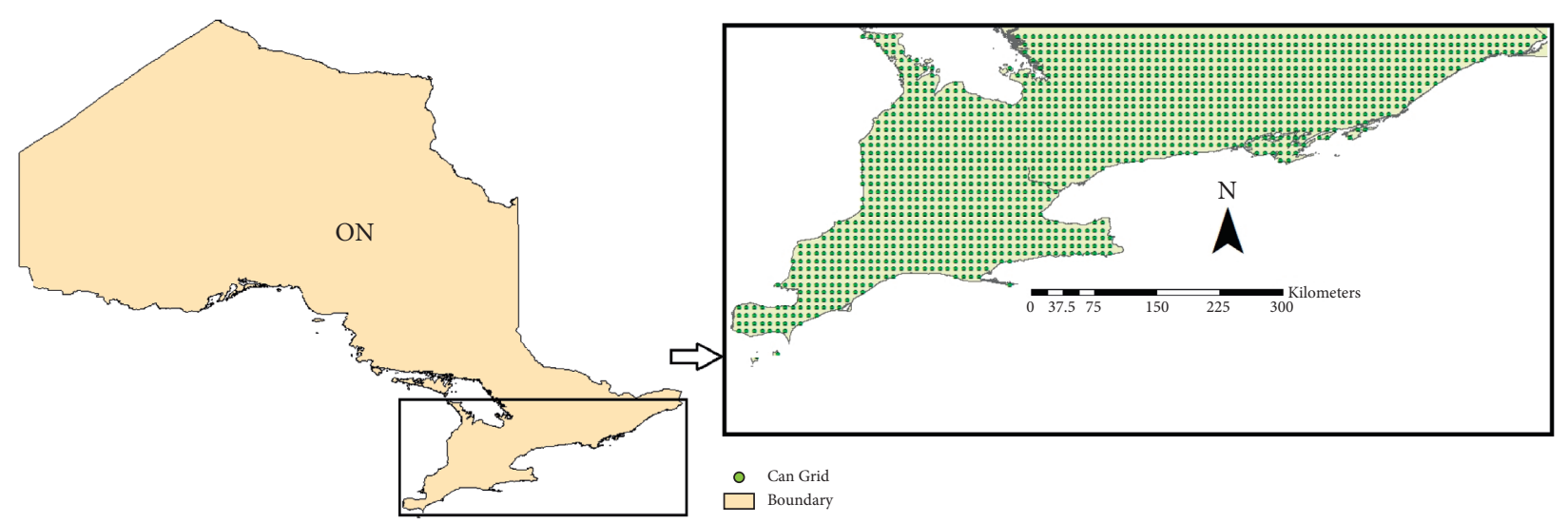

Figure 1: Study location in southern Ontario, Canada. Green circles represent each of the 1699 ANUSPLIN grid points $(\sim 10 \mathrm{~km} \times 10 \mathrm{~km})$ in the study area.

cover and precipitation during winter (snow-lake effect), and (3) decreases in summertime convective clouds and rainfall events. These effects are due to differences in the heat capacities of water and land surfaces and the rate of the Bowen ratio among the two surfaces and due to the large differences in moisture source especially from the Great Lakes [32, 33].

The observed daily precipitation and maximum and minimum $2 \mathrm{~m}$ air temperature datasets used for this study were extracted from gridded historical weather station data (CanGrid) produced by Natural Resources Canada using interpolated Environment Canada's observed station across Canada. This dataset [34] covers Canada (south to $60^{\circ} \mathrm{N}$ ) and contains daily variables from 1951 to 2013 on a Lambert conformal conic projection with $5^{\prime}$ arc minute spacing (equivalent to a resolution of roughly $10 \mathrm{~km}$ ). These climate data were generated using the "ANUSPLIN" software [35]. This dataset has been used in many climate change studies in the recent past (e.g., [36-38] and [8, 39, 40]). Canadian gridded data from 1699 CanGrid grid points located in southern Ontario corresponding to the boundaries of the study site over the period of 1951-2013 were used in this study (Figure 1). Based on the grid-points information, the total annual precipitation for this period varies from the lowest recorded value of $725 \mathrm{~mm}$ to $1162 \mathrm{~mm}$.

2.2. Copula Concepts. Copula is a statistical notion used to describe the nonlinear dependence between random variables and to establish joint distribution of these variables using their marginal functions. It is also described as a function that connects univariate distributions to a multivariate distribution describing the dependence among correlated variables. The main advantages of using copula approach are as follows: (1) flexibility in choosing arbitrary marginal and structure of dependence, (2) extension to more than two variables, and (3) separated analysis of marginal distributions and dependence structure [41, 42]. The joint distribution is fitted by estimating the marginal distributions of variables and their correspondence separately, which is not restricted to any parametric distribution (e.g., Gaussian distribution). Copula method has been widely used to examine interactions and associations between hydrological and/or climatological variables. De Michele and Salvadori [43] identified the relation between intensity and duration of storm rainfall in Italy by using Frank copula. Hao and AghaKouchak [44] used a set of parametric copulas to derive the Multivariate Standardized Drought Index from vectors of precipitation and soil moisture. Lee et al. [45] studied the influence of the tail shape of various copula functions (i.e., Gumbel, Frank, Clayton, and Gaussian) on drought bivariate frequency analysis. Renard and Lang [46] suggested applications of Gaussian copula on flood mitigation in France. Grimaldi and Serinaldi [47] have proved the adequacy of two copulas (Frank and Gumbel) on the flood characteristics analyzed for Kanawha River in West Virginia (United States). Chebana and Ouarda [48, 49] presented regional multivariate flood analysis using copula and multivariate L-moments, as also used in the study of Saad et al. [18] who have developed trivariate copula for flood analysis over the Richelieu River located in southern Quebec. A Gumbel copula was used by Leonard, Metcalfe, and Lambert [50] to couple the seasonal rainfall maxima marginal distributions on the Murray-Darling Basin, Australia. Adlouni and Ouarda [51] proposed the application of copula to analyze the dependence of the water level of Saint-Louis Lake on the maxima flow on the Chateauguay River in Quebec (Canada). Rosa and Leite [52] presented that Frank and Clayton copulas fit well in studying a relationship between maximal flow and volume in Portugal. To establish the relation between the different flood characteristics, Salarpour et al. [53] applied the t-copula on the Johor River in Malaysia. A Gumbel copula was selected as the most appropriate model for trivariate frequency analyses of peak discharges, hydrograph volumes, and suspended sediment concentrations in Bezak et al.'s work [54]. Also copula was used to describe flood peak and volume, flood peak and duration, and flood volume and duration $[55,56]$; drought severity and duration [45]; and heat waves and drought [57]. Therefore, copula function has been proved to a be very useful and effective tool for multivariate hydrological and climatological analysis and simulation. 
Mathematically, a copula is a multivariate probability distribution linking standard uniformly distributed marginals. Assuming that $X$ and $Y$ are pairs of random variables with cumulative distribution functions (CDF), $F(x)=\operatorname{Pr}[X \leq x]$ and $G(y)=\operatorname{Pr}[Y \leq y]$. By the Sklar [58] theorem, the joint two-dimensional distribution function of $X$ and $Y$, symbolized as $H(x, y)$ with the cumulative joint probability $p$, can then be generated as follows:

$$
p=\operatorname{Pr}[X \leq x, Y \leq y]=H(x, y)=C\{F(x), G(y)\},
$$

where $C:[0,1] \times[0,1] \longrightarrow[0,1]$ is defined as the copula function.

Here, $C(u, v)$ is an arbitrary two-dimensional copula function. The function $C$ has the following elementary properties [59]:

(1) For every $u$ and $v, C(u, 0)=C(0, v)=0$

(2) $C(u, 1)=$ uet $C(1, v)=v$

(3) For each $u_{1}, u_{2}, v_{1}$, and $v_{2}$, if $u_{1} \leq u_{2}$ and $v_{1} \leq v_{2}$, $C\left(u_{2}, v_{2}\right)-C\left(u_{2}, v_{1}\right)-C\left(u_{1}, v_{2}\right)+C\left(u_{1}, v_{1}\right) \geq 0$

A variety of copula families have been described in the literature (e.g., $[59,60]$. Copula families differ in their parameter numbers and in their dependence structure, which have bearing on their complexity. The parameters of copulas control the strength of dependence. These parameters are generally estimated using local optimization algorithms (e.g., [61-63], Bayesian (e.g., [64, 65]), L-moments approach (e.g., [66]), and exact maximum likelihood (EML) methods [67]). In this study, five copula functions were used to describe interdependence between precipitation and temperature variables: Gaussian, Student, Frank, Clayton, and Gumbel (Table 1). These copulas belong to elliptical (Gaussian and t-copula) [60] and Archimedean (Frank, Clayton, and Gumbel copulas) families [59]. Note that elliptical copulas are often employed for simple dependency structure $[68,69]$. Therefore, Archimedean family of copulas is more desirable for hydrological analyses because it can be easily constructed and can be applied whether the correlation between the variables is positive or negative [56]. These copulas were selected for analysis because they have been commonly used to evaluate climate variable interdependence in hydrological and climatological studies.

2.3. Analysis Procedure. Available climate data were first treated with the following criteria: days with no precipitation $(<0.10 \mathrm{~mm})$ were removed from analysis and all other days were grouped into seasons (December-January-February (DJF), March-April-May (MAM), Jun-July-August (JJA), and September-October-November (SON)). To fit the joint distribution between temperature and precipitation using copula approach, the following procedure was used:

(1) During the first step of analysis, adequate marginal distribution (probability distribution function, PDF) is chosen for each of the studied variables. In fact, the marginal distribution of daily average temperature and daily total precipitation in the study region was identified. Identifying the fitted probability distribution allows predicting the probability of exceedance for a specified magnitude (quantile) or the magnitude associated with a specific exceedance probability. There is no theoretical basis for the choice of probability distribution and the parameter estimation method. In this study, twelve probability distributions were fitted for each grid and season. The fitted PDFs are Beta, Exponential, Extreme value, Gamma, Generalized extreme value, Generalized Pareto, Inverse Gaussian, Logistic, Log-logistic, Log-normal, Normal, and Weibull (see Table 2). Several methods to estimate the parameters associated with these distributions are presented in the literature, that is, the maximum likelihood method (e.g., [70, 71]), method of moments (e.g., [72]), and L-moment method (e.g., [73]). In this study, the maximum likelihood method was used. The selection of the best fit distribution for each variable (i.e., best marginal distribution fit of the grid data) is based on the Bayesian information criterion (BIC) proposed by Schwartz (1978). The smallest BIC values identify the best fit distribution [74].

(2) In the second step of the analysis, the cumulative distribution function (CDF) of these distributions is used to compute the marginal cumulative probabilities $u_{i}=F\left(x_{i}\right)$ and $v_{i}=G\left(y_{i}\right)$. This computation assumes that $F_{\mathrm{i}}$ and $G_{\mathrm{i}}$ are the selected PDFs for total precipitation and daily average temperature for the grid $i$, respectively. Note that $u_{i}$ and $v_{i}$ are strictly increasing functions and range within the interval $[0,1]$.

(3) In the third step of the analysis, five copula functions (as defined in Table 1) are fitted to the marginal cumulative probabilities of daily average temperature and total precipitation. To select the suitability (best fit) copula function, a method based on the comparison of theoretical and empirical copula functions was used. In detail, for each copula function, the root mean square error defined as the average square distance between theoretical and empirical copulas was calculated. The appropriate copula of each grid is the one that has the lowest root mean square error. Note that the parameters of the copula were estimated using the exact maximum likelihood (EML) method [67].

Once the joint distribution of each grid is established (including the margins, copula, and their parameters), it can be used, for example, to calculate the joint risk (probability). Joint probability of precipitation and mean temperature is very important for the management and assessment of the risks imposed by extreme meteorological and hydrological events. It helps in the management of resources such as agriculture sector productivity. Generally, in the bivariate case, four simultaneous events can be of interest: (1) simultaneous exceedance $\{P \geq p, T \geq t\}$, (2) exceedance-nonexceedance $\{P \geq p, T \leq t\}$, (3) non-exceedance-exceedance $\{P \leq p, \mathrm{~T} \geq t\}$, and (4) simultaneous nonexceedance $\{P \leq p$, $T \leq t\}$. In this study, we mainly focused on computing the probability of concurrent extreme temperature and 
TABLE 1: List of copula members used in this study.

\begin{tabular}{|c|c|}
\hline $\begin{array}{l}\text { Copula } \\
\text { name }\end{array}$ & Copula formula \\
\hline Gaussian & $\begin{array}{r}C(u, v)=\int_{-\infty}^{\Theta^{-1}(u)} \int_{-\infty}^{\Theta^{-1}(v)}\left(1 / 2 \pi \sqrt{1-\rho^{2}}\right) e^{\left(y^{2}-x^{2}-2 \rho x y\right) / 2\left(1-\rho^{2}\right)} \mathrm{d} x \mathrm{~d} y ; x, y \in \mathbb{R}, \rho \text { is the linear correlation, and } \Theta \text { is the normal } \\
\text { standardized function. }\end{array}$ \\
\hline Student & $\begin{array}{c}C(u, v)=\int_{-\infty}^{t_{\kappa}^{-1}(u)} \int_{-\infty}^{t_{\kappa}^{-1}(v)}\left(1 / 2 \pi \sqrt{1-\rho^{2}}\right) e^{\left(1+\left(\left(y^{2}-x^{2}-2 \rho x y\right) / 2\left(1-\rho^{2}\right)\right)\right)^{(-(\kappa+2) / 2)} \mathrm{d} x \mathrm{~d} y ; x, y \in \mathbb{R}, \rho \text { is the linear correlation coefficient, and }} \\
t^{-1} \text { is the inverse cumulative distribution function }(\mathrm{CDF}) \text { for Student's } t \text {-distribution with } \kappa \text { degree of freedom. }\end{array}$ \\
\hline $\begin{array}{l}\text { Gumbel } \\
\text { Clayton } \\
\text { Frank }\end{array}$ & $\begin{aligned} C(u, v) & =e^{\left\{-\left[(-\ln u)^{\theta}+(-\ln v)^{\theta}\right]^{1 / \theta}\right\}}, \text { where } \theta \text { measures the dependency between } u \text { and } v \\
C(u, v) & =\left(u^{-\theta}+v^{-\theta}-1\right)^{(-1 / \theta)}, \text { where } \theta \text { measures the dependency between } u \text { and } v . \\
C(u, v)=-(1 / \theta) \ln [1 & \left.+\left(\left(\left(e^{-\theta u}-1\right)\left(e^{-\theta v}-1\right)\right) /\left(e^{-\theta}-1\right)\right)\right], \text { where } \theta \text { measures the dependency between } u \text { and } v .\end{aligned}$ \\
\hline
\end{tabular}

TABLE 2: The fitted marginal distribution of daily average temperature and daily total precipitation.

\begin{tabular}{|c|c|}
\hline Name & Function \\
\hline Beta & $\begin{array}{l}\qquad y=f(x ; a, b)=(1 / B(a, b)) x^{a-1}(1-x)^{b-1} I_{[0,1]}(x) \\
\text { where } a, b>0 \text { are the shape parameters; } B(.) \text { is the Beta function; and } I_{[0,1]} \text { is the indicator function. }\end{array}$ \\
\hline Exponential & $\begin{array}{c}y=f(x ; y)=(1 / \mu) e^{-e / \mu} \\
\text { where } \mu \text { is the mean. }\end{array}$ \\
\hline Extreme value & $\begin{array}{l}\qquad \begin{array}{l}y=f(x ; \mu, \sigma)=\sigma^{-1} e^{(x-\mu / \sigma)} e^{-e(x-\mu / \sigma)} \\
\text { where } \mu \text { and } \sigma \text { are, respectively, the location and scale parameters. }\end{array}\end{array}$ \\
\hline Gamma & $\begin{array}{c}y=f(x ; a, b)=\left(1 /\left(b^{a} \Gamma(a)\right)\right) x^{a-1} e^{(-x / b)} \text {, where } a \text { and } b \text { are the shape and scale parameters and } \Gamma(\cdot) \text { is the Gamma } \\
\text { function. }\end{array}$ \\
\hline $\begin{array}{l}\text { Generalized } \\
\text { extreme value }\end{array}$ & $\left\{\begin{array}{cl}y=f(x ; k, \mu, \sigma)=(1 / \sigma) e^{-(1+(k(x-\mu) / \sigma))^{(-1 / k)}}(1+(k(x-\mu) / \sigma))^{-1-(1 / k)}, & \text { for } k \neq 0 \text { and }(1+k(x-\mu / \sigma))>0 \\
y=f(x ; 0, \mu, \sigma)=(1 / \sigma) e^{\left(-e^{(-((x-\mu) / \sigma))}-((x-\mu) / \sigma)\right)}, & \text { for } k=0, \\
\text { where } \mu, \sigma, \text { and } k \text { are, respectively, the location, scale, and shape parameters. }\end{array}\right.$ \\
\hline $\begin{array}{l}\text { Generali } \\
\text { Pareto }\end{array}$ & $\begin{array}{cl}y=f(x ; k, \mu, \sigma)=(1 / \sigma)(1+k((x-\theta) / \sigma))^{-1-(1 / k),}, & \text { for } \theta<x \text { when } k>0, \text { or for } \theta<x<\theta-(\sigma / k) \text { when } k<0, \\
y=f(x ; k, \mu, \sigma)=(1 / \sigma) e^{(-(x-\theta) / \sigma),} & \text { for } \theta<x \text { when } k=0, \\
\text { where } k, \sigma, \text { and } \theta \text { are, respectively, the shape, scale, and threshold parameters. }\end{array}$ \\
\hline Inverse Gaussian & $\begin{array}{l}\qquad f(x ; \mu, \lambda)=\sqrt{\left(\lambda / 2 \pi x^{3}\right)} e^{\left(-\left(\lambda(x-\mu)^{2}\right) / 2 \mu^{2} x\right)}, \text { for } x>0 \text {, } \\
\text { where } \mu \text { and } \lambda \text { are, respectively, the mean and shape parameters. }\end{array}$ \\
\hline Logistic & $\begin{array}{l}\qquad f(x ; \mu, \sigma)=\left(e^{x-\mu / \sigma} / \sigma\left(1+e^{x-\mu / \sigma}\right)^{2}\right) \\
\text { where } \mu \text { and } \sigma \text { are, respectively, the mean and scale parameters. }\end{array}$ \\
\hline Log-logistic & $\begin{array}{l}f(x ; \mu, \sigma)=(1 / \sigma)(1 / x)\left(e^{(\log (x)-\mu) / \sigma} /\left(1+e^{(\log (x)-\mu) / \sigma}\right)^{2}\right) \quad x \geq 0 \\
\text { where } \mu \text { and } \sigma \text { are, respectively, the mean and scale parameters. }\end{array}$ \\
\hline Log-normal & $f(x ; \mu, \sigma)=(1 /(x \sigma \sqrt{2 \pi})) e^{-\left((\log x-\mu)^{2} / 2 \sigma^{2}\right)}, \quad$ for $x>0$ \\
\hline Normal & $\begin{array}{l}\text { If } X \text { follows the log-normal distribution with parameters } \mu \text { and } \sigma \text {, then } \log (X) \text { follows the normal distribution with mean } \\
\qquad \mu \text { and standard deviation } \sigma .\end{array}$ \\
\hline & $\begin{array}{l}\qquad \begin{array}{l}y=f(x ; \sigma, k)=(k / \sigma)(x / \sigma)^{k-1} e^{-(x / \sigma)^{k}} \\
\text { where } \sigma \text { and } k \text { are, respectively, the scale and shape parameters. }\end{array}\end{array}$ \\
\hline
\end{tabular}

precipitation events including wet/cool (denoted by $\left.P_{w / c}\right)$ in the winter (DJF) and dry/hot (denoted by $P_{d / h}$ ) in the summer (JJA). Following Zhou and Liu [75], in order to capture a large number of events, we used the $25^{\text {th }}$ and $75^{\text {th }}$ quantile thresholds of $T$ and $P$ to define these two probabilities:

$$
\begin{aligned}
& P_{w / c}=\operatorname{Pr}\left[P \geq p_{75}, T \leq t_{25}\right], \\
& P_{d / h}=\operatorname{Pr}\left[P \leq p_{25}, T \geq t_{75}\right],
\end{aligned}
$$

where $p_{25}, p_{75}, t_{25}$ and $t_{75}$ are, respectively, the $25^{\text {th }}$ and $75^{\text {th }}$ quantile thresholds of precipitation and temperature. To quantify the usefulness of introducing the dependence between precipitation and temperature, these two probabilities were computed for each grid by assuming that $P$ and $T$ are independent (denoted as $\left(P_{w / c}\right)_{I}$ and $\left.\left(P_{d / h}\right)_{I}\right)$ and dependent (denoted as $\left(P_{w / c}\right)_{D}$ and $\left.\left(P_{d / h}\right)_{D}\right)$ variables. Therefore, using some probability manipulation, they can be defined as

$$
\begin{aligned}
\left(P_{w / c}\right)_{I}= & \operatorname{Pr}\left[P \geq p_{75}, T \leq t_{25}\right]=\operatorname{Pr}\left[P \geq p_{75}\right] \times \operatorname{Pr}\left[T \leq t_{25}\right] \\
= & \left(1-F\left(p_{75}\right)\right) \times G\left(t_{25}\right), \\
\left(P_{d / h}\right)_{I}= & \operatorname{Pr}\left[P \leq p_{25}, T \geq t_{75}\right]=\operatorname{Pr}\left[P \leq p_{25}\right] \times \operatorname{Pr}\left[T \geq t_{75}\right] \\
= & F\left(p_{25}\right) \times\left(1-G\left(t_{75}\right)\right), \\
\left(P_{w / c}\right)_{D}= & \operatorname{Pr}\left[P \geq p_{75}, T \leq t_{25}\right]=G\left(t_{25}\right) \\
& -C\left\{1-F\left(p_{75}\right), G\left(t_{25}\right)\right\}, \\
\left(P_{d / h}\right)_{D}= & \operatorname{Pr}\left[P \leq p_{25}, T \geq t_{75}\right]=F\left(p_{25}\right) \\
& -C\left\{F\left(p_{25}\right), 1-G\left(t_{75}\right)\right\},
\end{aligned}
$$



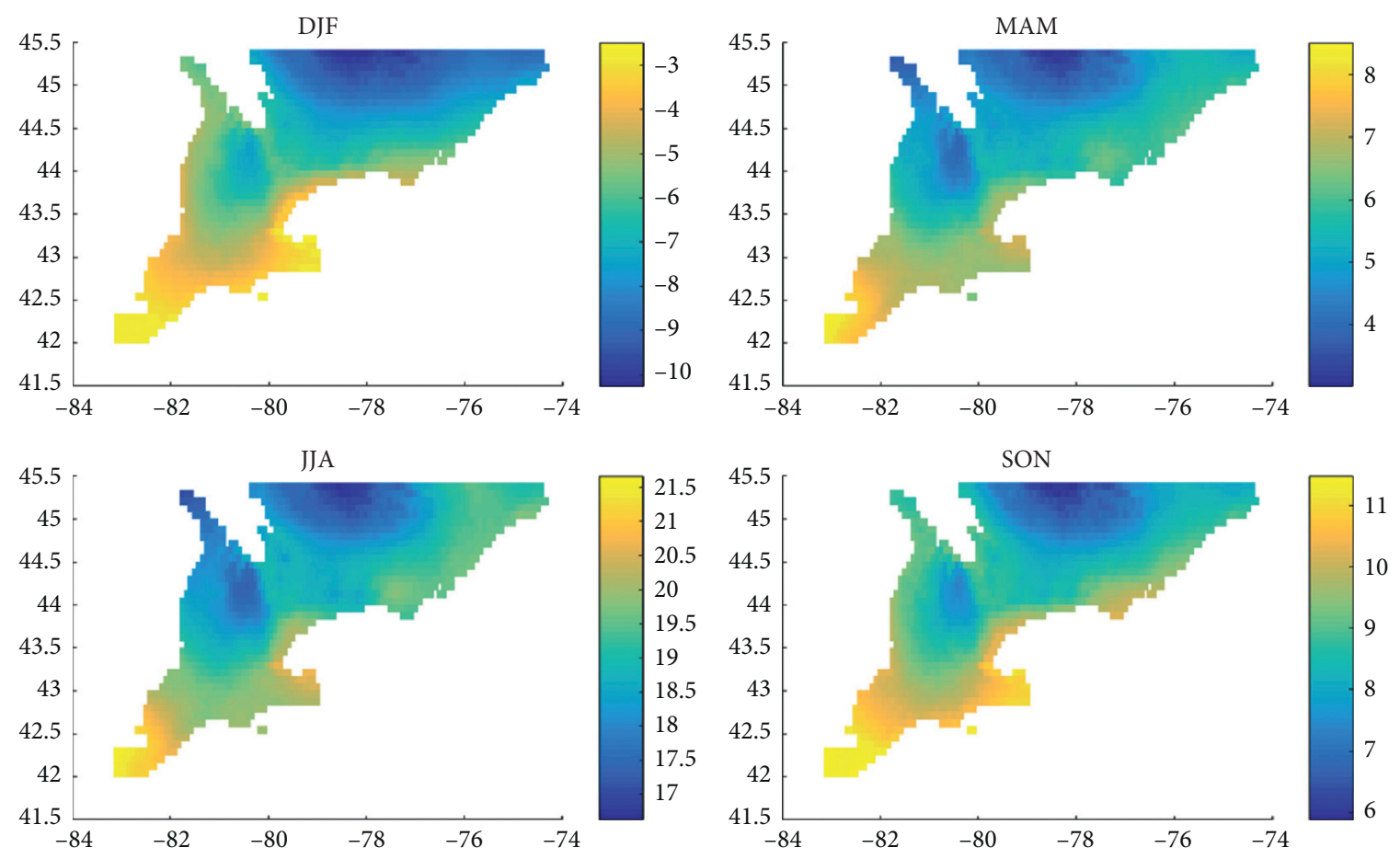

(a)
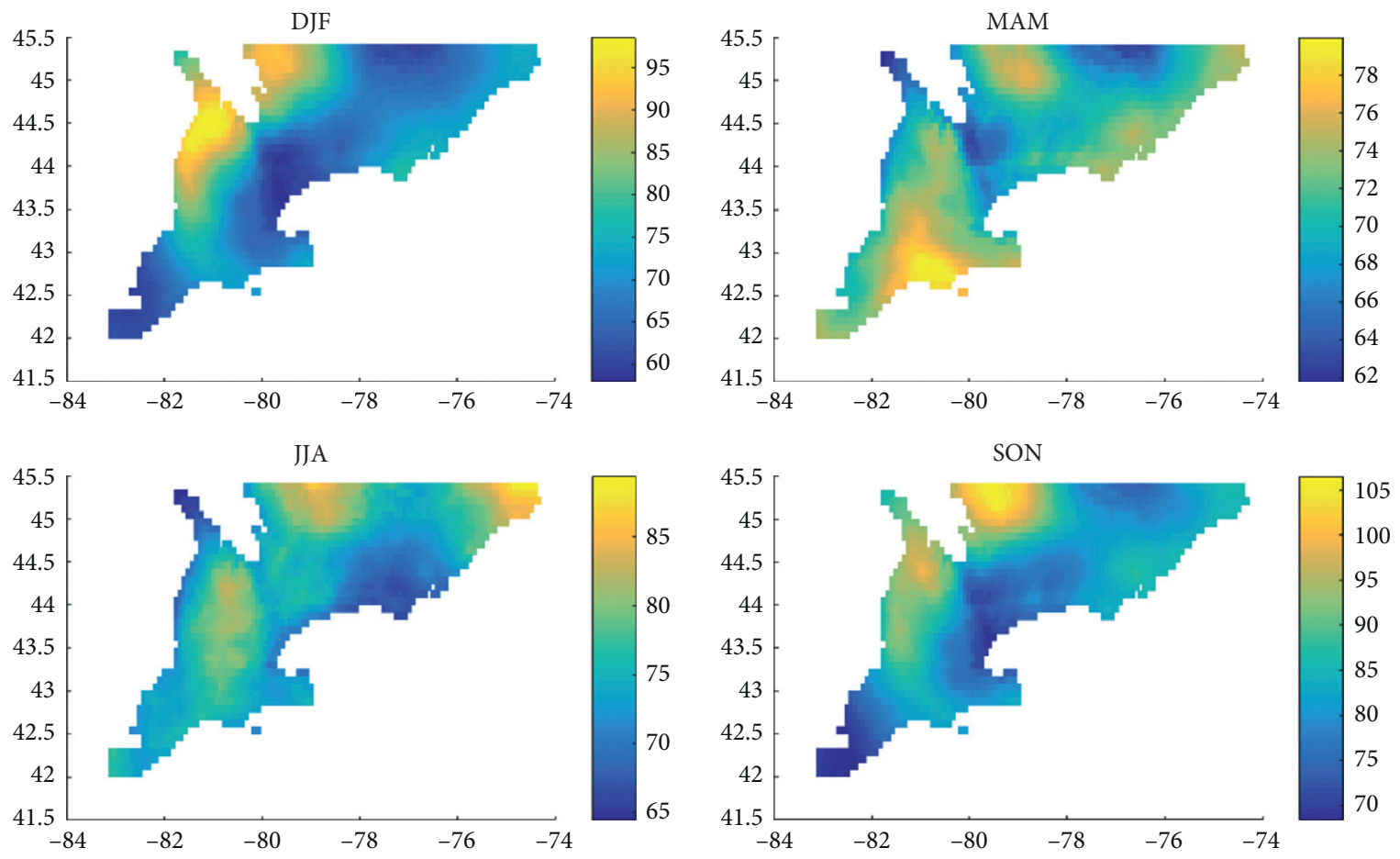

(b)

Figure 2: (a) Spatial variability of seasonal average temperature $\left({ }^{\circ} \mathrm{C}\right)$ and (b) spatial variability of seasonal total precipitation $(\mathrm{mm})$ temporally averaged (over the period of 1960-2013) for the four seasons using ANUSPLIN data. Seasons are defined as DJF for winter, MAM for spring, JJA for summer, and SON for fall.

where $F$ and $G$ are the selected PDFs for daily total precipitation and daily average temperature and $C$ represents the best fitted copulas for the selected grid. After computing these probabilities for each grid of the study region, two maps showing the differences of likelihoods between dependent and independent (i.e., map for $\left[\left(P_{w / c}\right)_{D}-\left(P_{w / c}\right)_{I}\right]$ and one for $\left.\left[\left(P_{d / h}\right)_{D}-\left(P_{d / h}\right)_{I}\right]\right)$ were developed. These maps showed the presence of risk not covered in the estimation of 
these concurrent extremes by ignoring the dependence between temperature and precipitation. More details are presented in the Results section.

\section{Results}

The spatial variability of monthly mean temperature that was averaged over the study period for all four seasons is shown in Figure 2(a). A high variability in temperatures between seasons demonstrates the necessity of seasonal-scale copula analyses for this study to capture variability and extreme events. Monthly average temperature varied from -20 to $3^{\circ} \mathrm{C}$ in the winter (DJF), from -10 to $19^{\circ} \mathrm{C}$ in the spring (MAM), from 13 to $26^{\circ} \mathrm{C}$ in the summer (JJA), and from -5 to $20^{\circ} \mathrm{C}$ in the fall (SON). During all seasons, the highest temperatures were found in southwestern area (urban centers) close to the Lake Ontario and Lake Erie in the western portion of the study area. The lowest temperature was found in the northern (rural) areas and at high elevations in the northwest portion of the study area. Overall, as spatial variability, we observed approximately $+5^{\circ} \mathrm{C}$ gradient from the southwest to the north across the study region.

The spatial variability of total precipitation by season and temporally averaged over the studied period is shown in Figure 2(b). Total monthly precipitation varied from 178 to $285 \mathrm{~mm}$ for DJF, from 185 to $240 \mathrm{~mm}$ for MAM, from 195 to 265 for JJA, and from 208 to $315 \mathrm{~mm}$ for SON. Variability in seasonal total precipitation was spatially more complex than average temperature, reflecting combined effects in surface condition and topography. The lowest precipitation occurred in the eastern and southern parts of the study region close to the Lake Ontario and Erie Lakes but with a maximum in precipitation in the western part close to the Huron Lake and Georgian Bay from fall to spring months (i.e., snow-lake effect). Day-and-night heating/cooling and wind patterns adjacent to the lakes were more variable compared to areas located further inland. Increased variability in these on-shore winds may have contributed to lower/higher precipitation adjacent to the lakes in southernmost/westernmost Ontario. The area of highest monthly precipitation was observed in the western and northern parts of the study region east of Georgian Bay and Lake Huron is also a high elevation sector relative to the southern part of the study site and higher forest cover. Weather patterns in this area were also more influenced by precipitation or known snow bands extending eastwards of Lake Huron and Georgian Bay in the west. These regional influences may have contributed to higher precipitation in this part of the study area. In general, a high seasonal variability (standard deviation not shown) was found during the fall and winter seasons when compared to variability during spring and summer.

Figure 3(a) shows the spatial variability of Spearman rank correlation between daily data with total precipitation and daily average temperature for all four seasons. The $p$ values of corresponding significance test are shown in Figure 3(b). The two main advantages of the Spearman rank correlation test as opposed to simple linear correlation test are the following: (1) it can be computed without any assumption about the normal distribution of data and (2) it has low sensitivity for inhomogeneous time series. This correlation has been used for trend analyses in climatologic and hydrologic time series [76]. A positive rank correlation was found between daily total precipitation and average temperature across the studied area and for all four seasons. Spatially, correlation was in most significant grid point within the entire study area. The highest correlation was observed in western parts in the spring and autumn. Also a high correlation was observed in the central parts of studied area adjacent to the Erie Lakes and Huron in the summer but with low correlation values outside of this area. This central and southern region was proportionally warmer and fog occurrence was higher as compared to elsewhere in the study area. Isaac and Stuart [21] show that, on $90 \%$ of days during which fog occurred, precipitation was also reported. Therefore, the portion of the study site with common fog days was expected to have a large number of days with precipitation. In general, as suggested by Isaac and Stuart [21] from a station-scale study, more precipitation falls during warm weather conditions during the winter over southern Ontario and Quebec.

Figure 4(a) shows the best fitted distribution (PDF) for seasonal daily average temperature from 1951 to 2013 for the study area. To show the spatial and temporal change of PDF that may exist at the extreme ends of the study region, two grids were selected: one in the furthest north east (grid 1) and the other in the furthest southwest (grid 1699) (Figure 4(b)). Selected distribution was found to vary spatially and seasonally between the two ends of the study area. During the winter season, based on average temperature, the studied area was grouped into two different regions based on temporal data distribution: (1) the southwestern part that followed a normal distribution curve and (2) the northeastern part that followed a GEV distribution curve with a high negative shape parameter (GEV type III). The shape parameter belonged to a narrow range, approximately from -8 to -10 . The extreme cold temperature in the northeastern part of the study region during winter can explain the use of GEV III (Figure 4(b), red curve). GEV with a positive shape parameter (GEV type II) was found to have the best GEV distribution for spring and fall seasons. The shape parameter varied spatially between 2 and 5 during spring and between 5.5 and 9.5 during fall. The observed variation in shape parameters can be explained by the large temporal variability of daily average temperature that occurred during these two seasons, with nonlinear feedbacks according to the snow cover and frozen conditions of the ground, which affects diabatic fluxes and underlying heating/cooling process (Figure 4(b)). The positive shape parameter value implies a heavy tail distribution. The spring and fall data distributions show that extreme values occurred more frequently relative to other values. A two-parameter Weibull distribution with large positive shape was observed for summer data (Figure 4(b)).

Figure 5 shows the best fitted distribution for seasonal total precipitation from 1951 to 2013 for the study area (5A) and the PDFs of daily total precipitation at grids 1 and 1699 for different seasons (5B). The best fit distribution was 

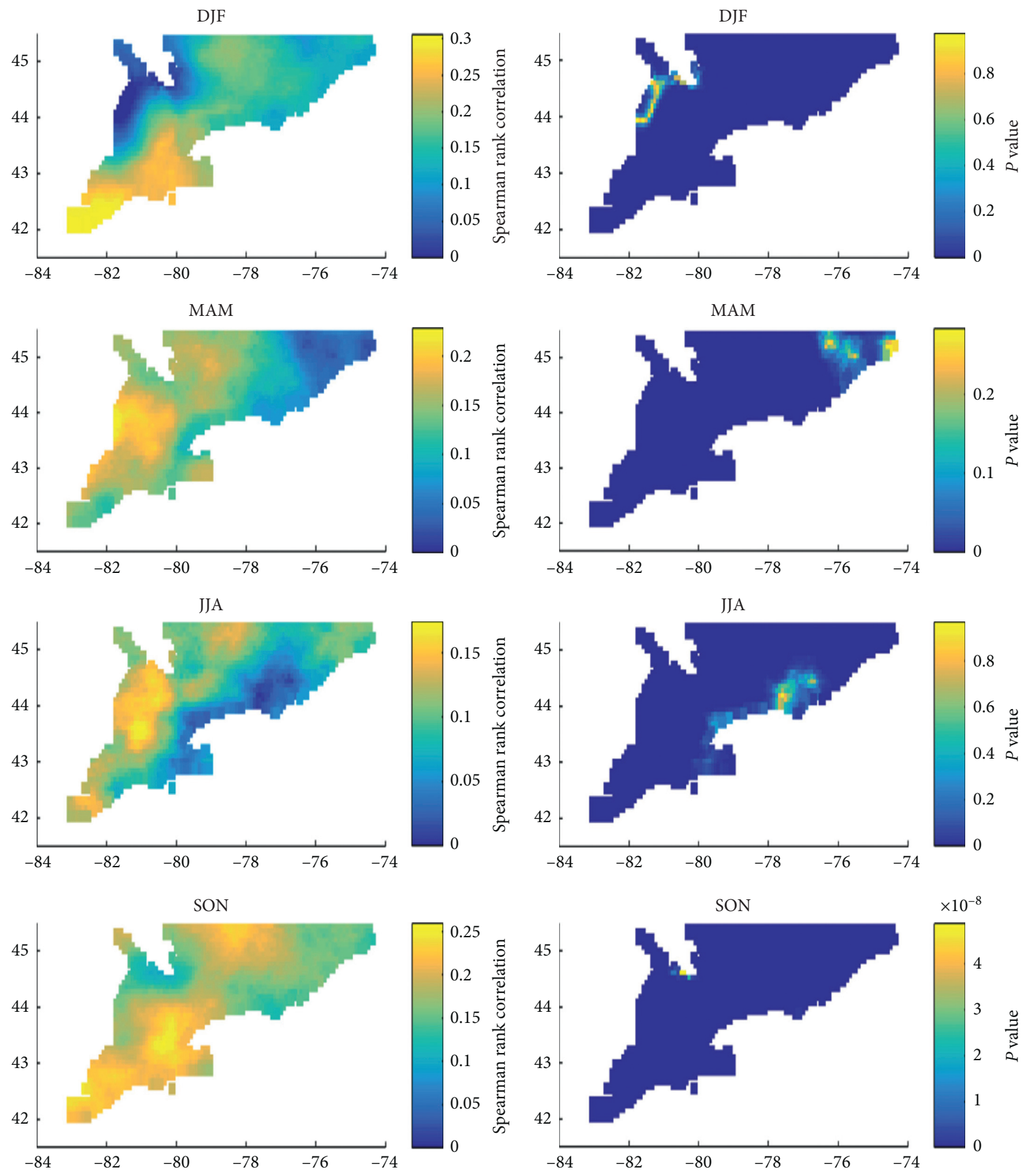

(a)

(b)

Figure 3: Spearman's rank correlation between daily nonzero precipitation and daily average temperature data (a). The $p$ values of significance test (b). A small $P$ value (less than 0.05 ) means a significant correlation.

observed to change spatially and seasonally with high spatial variability during spring and summer. This was an expected result due to the high spatial variability of precipitation processes that occurred during these seasons. Log-normal (LN) and Generalized Pareto (GP) were found to be the best distributions to fit to the daily data during all four seasons. LN distribution assumes that the logarithm of daily total precipitation is normally distributed and is useful when the variable of interest is skewed to the right. $\mathrm{LN}$ was found to be the best distribution in grids to fit with proportionally low precipitation amount. Additionally, GP was found to be the best distribution to fit data in grids with large daily precipitation amount.

Figure 6 shows the mean square error (MSE) between theoretical and empirical copula functions of all 1699 grids. For each grid, the best copula function that fits the joint 

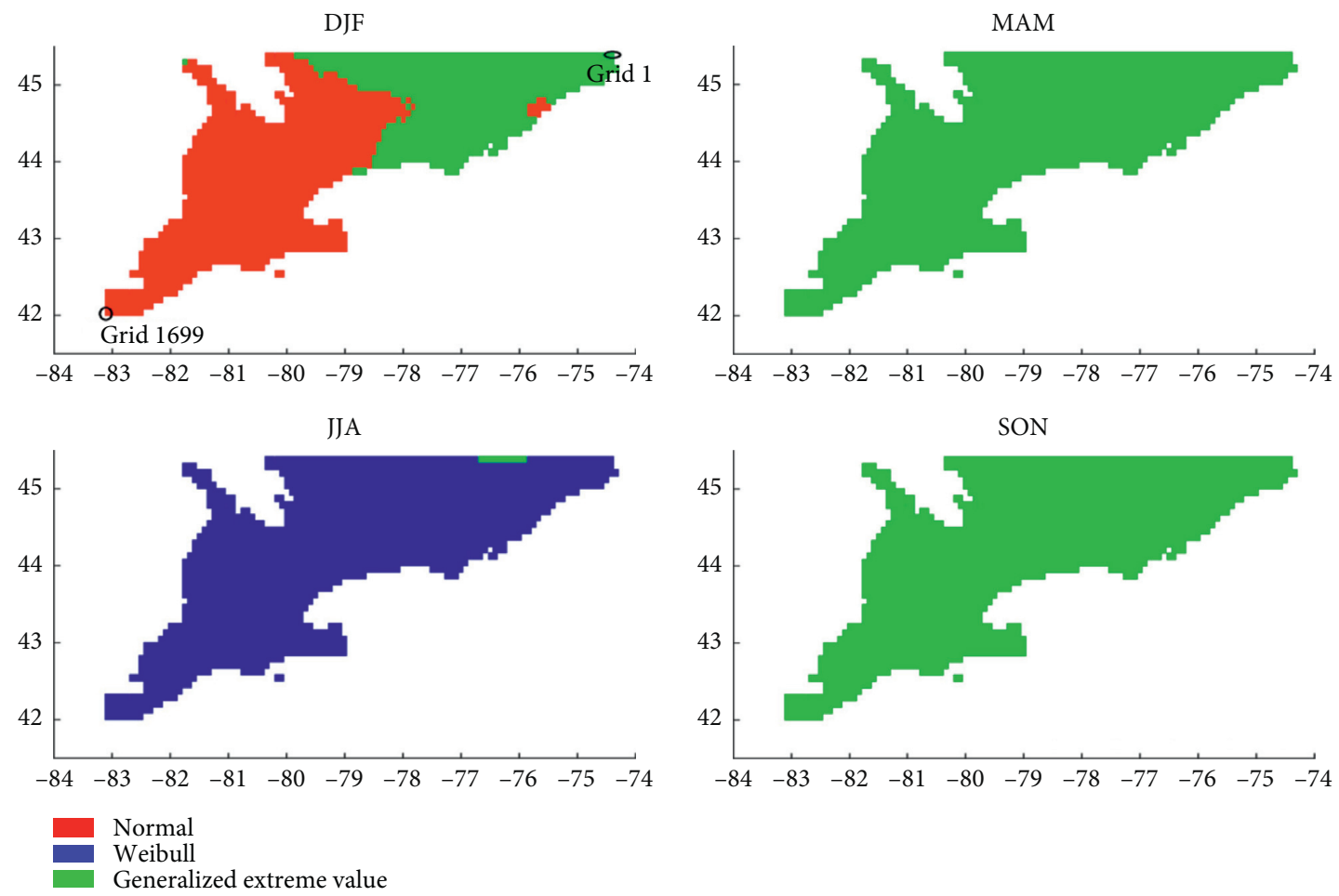

(a)
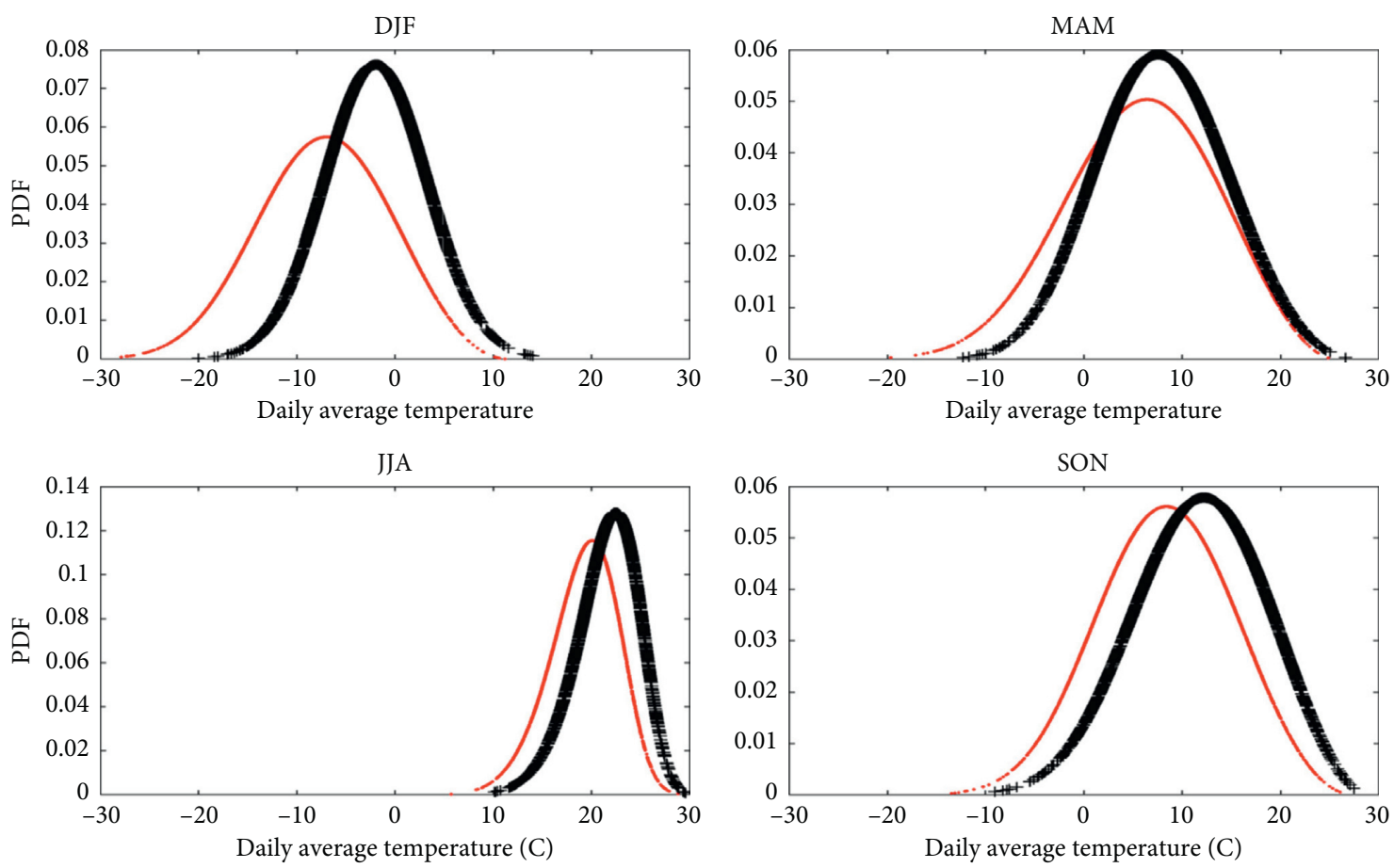

- Grid 1

+ Grid 1699

(b)

Figure 4: (a) Best parametric probability distribution function (PDF) (marginal distribution) in terms of the Bayesian Information Criteria fitted for historical daily averaged temperature data and (b) probability distribution function of daily averaged temperature of grids 1 (red) and 1699 (black), respectively. 

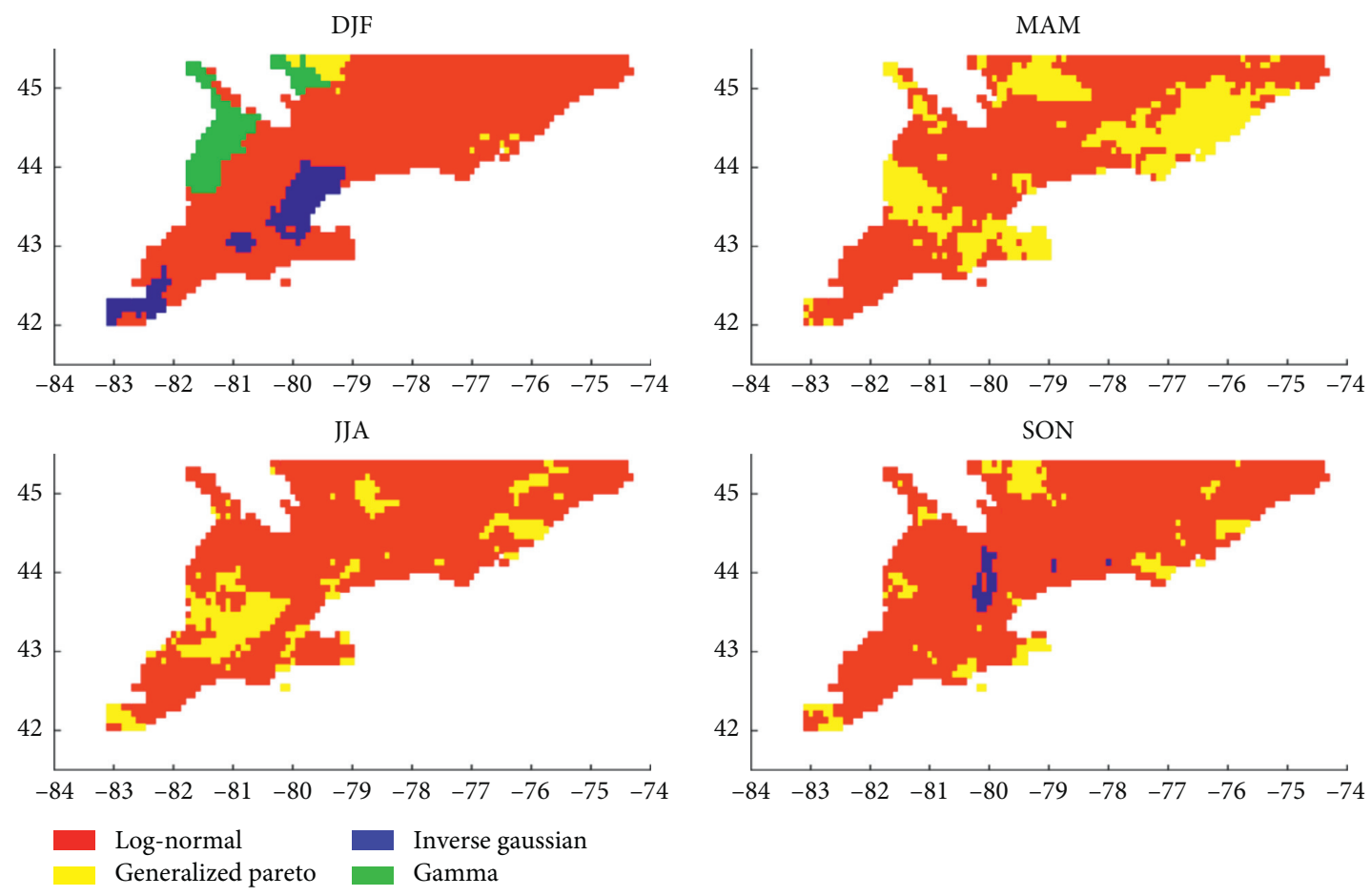

(a)
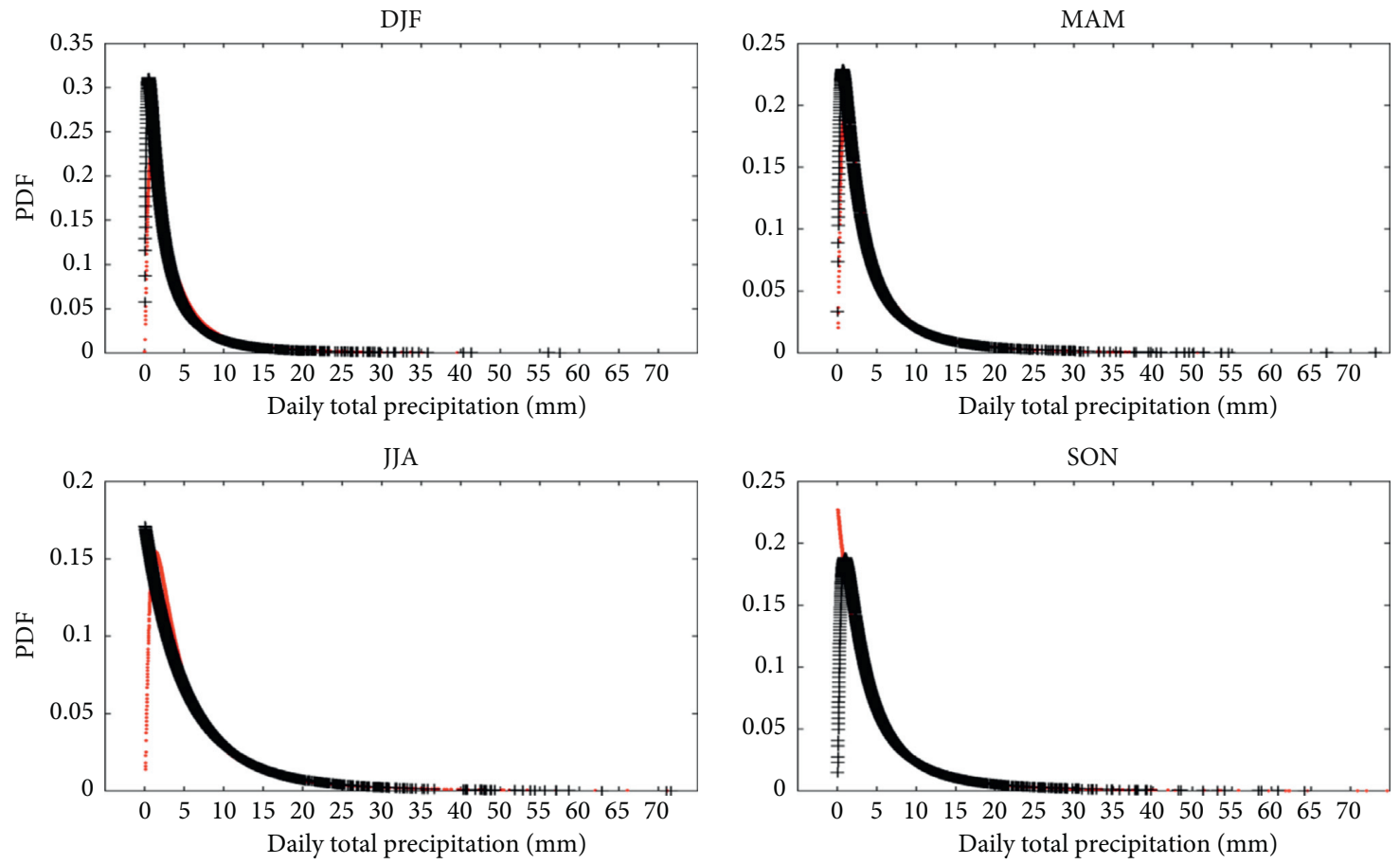

- Grid 1

+ Grid 1699

(b)

FIGURE 5: (a) Best parametric probability distribution function (PDF) (marginal distribution) in terms of the Bayesian Information Criteria fitted for historical daily nonzero precipitation data and (b) probability distribution function of daily nonzero precipitation of grids 1 (red) and 1699 (black), respectively. 

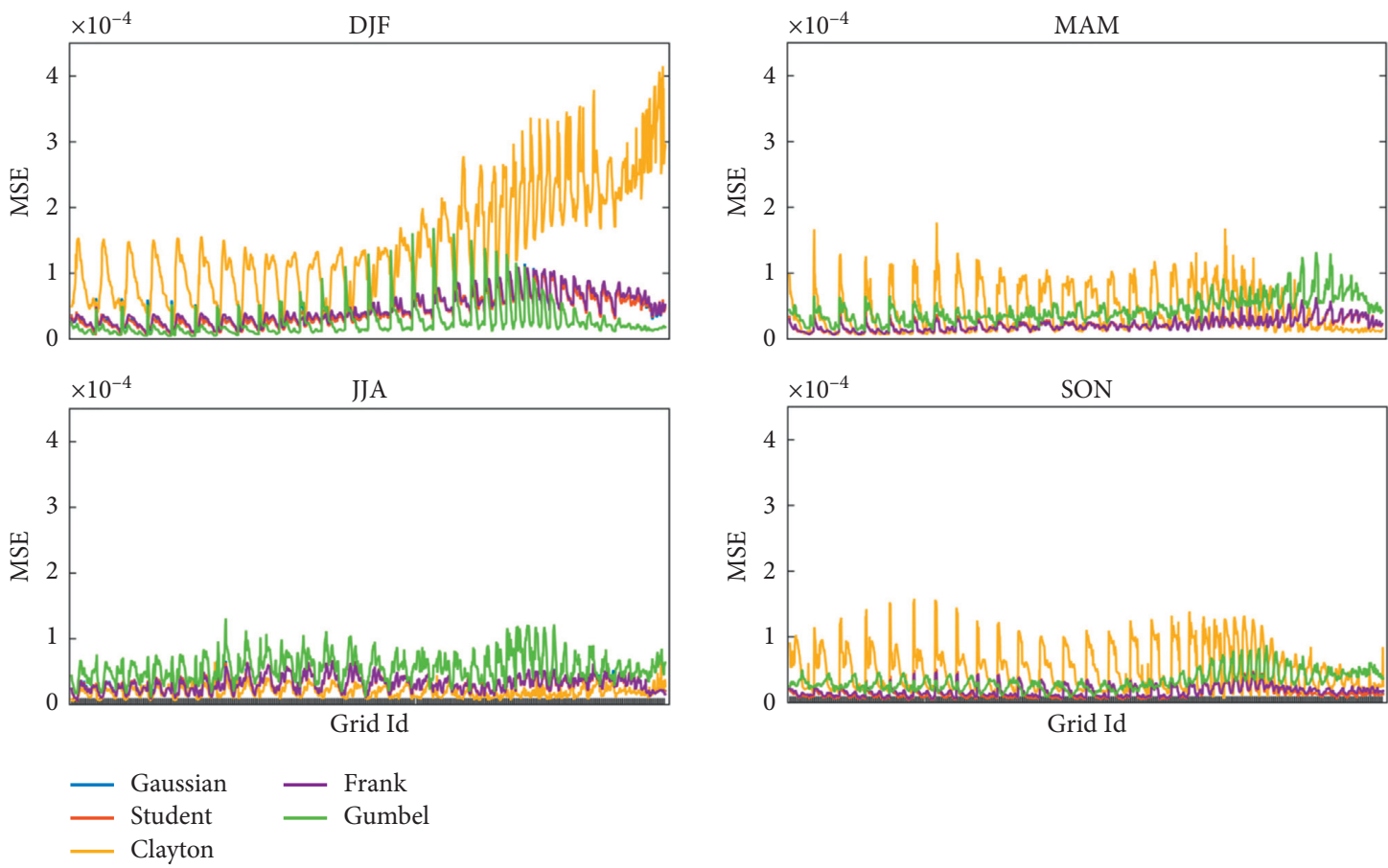

Grid Id

(a)
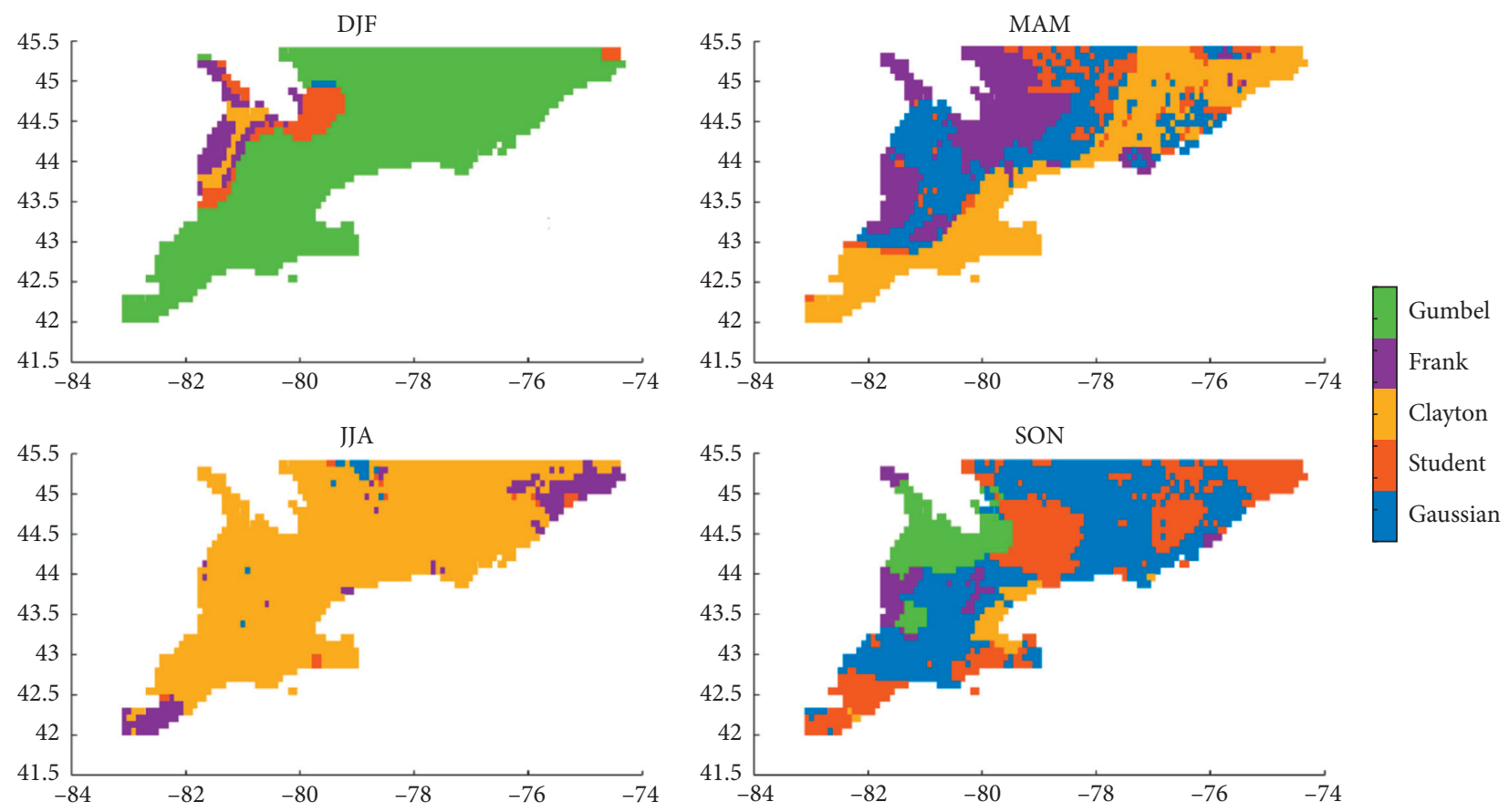

(b)

FiguRE 6: (a) Mean square error (MSE) of the 1699 grids computed using theoretical and empirical copula functions and (b) best copula function in terms of minimizing the MSE fit to the joint precipitation and average temperature data in the studied region.

distribution of precipitation and temperature is the one that minimizes MSE. In general, no copula was the best fit for all seasons and/or grids. That was expected due to differences in geographical and geophysical conditions across the region which influence temperature and precipitation variations. Less variability in terms of best copula was observed during winter and summer as compared to variability of best copula during spring and fall. Copula variation can be explained by the fact that temperature has the same positivity sign for all grids during winter and summer (i.e., positive for summer and negative for winter) which is not the case during spring and fall (whereas the temperature positivity sign depends upon the selected grid). Gumbel was found to be the best copula during winter and Clayton copula was the best 


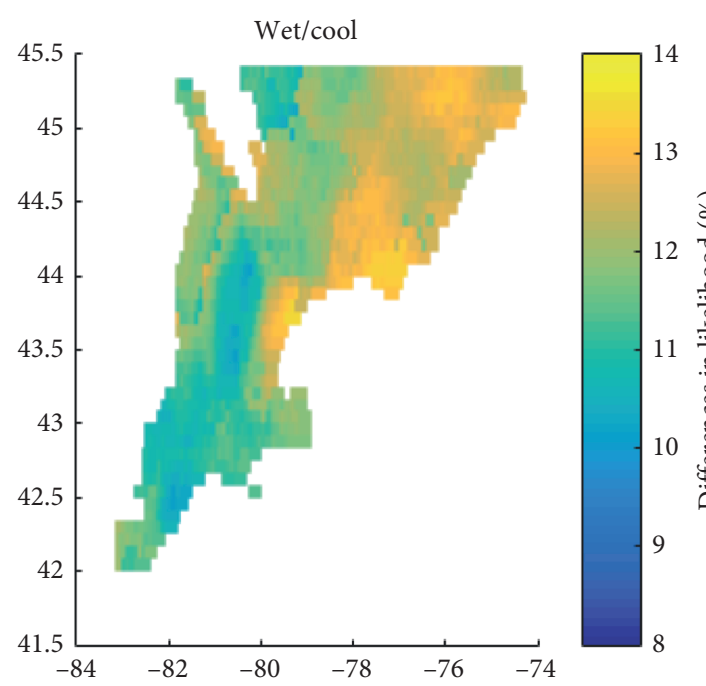

(a)

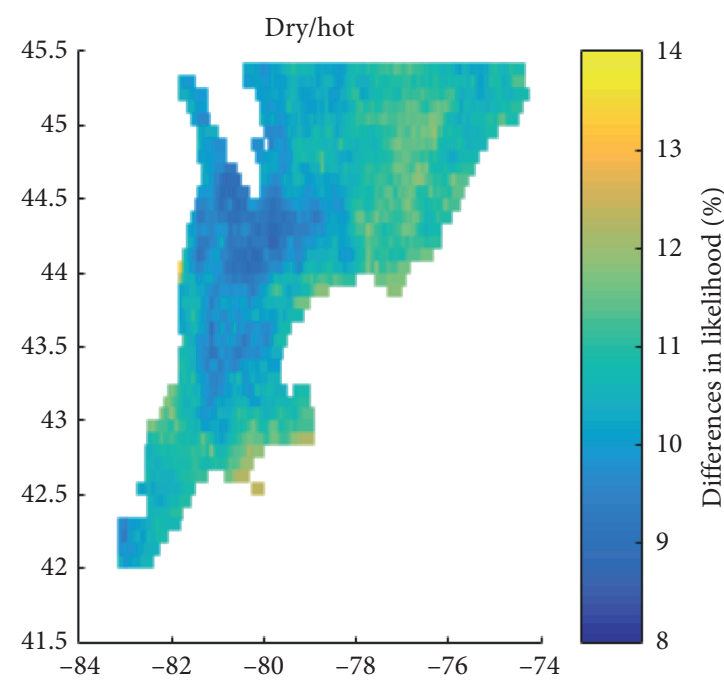

(b)

Figure 7: Differences between likelihoods of concurrent extremes ((a) wet/cool in the winter and (b) dry/hot in the summer) by supposing, respectively, that $P$ and $T$ are dependent and independent (likelihood dependent and likelihood independent).

performer during summer. These two copulas are asymmetric and belong to the Archimedean family. Gumbel copula is used for modelling heavy dependencies in right tail, which means that more precipitations in winter are generally related to warm weather in this region. In fact, warmer air can contain more water vapor than cooler air, which can result in higher probability of more intense precipitation (i.e., Clausius-Clapeyron relationship). Therefore, Clayton copula is used for modelling heavy dependencies in left tail, explaining the dependency between low amount precipitation and extreme temperature in summer. Due to the mechanisms mentioned previously in this section, greater variability in temperature and precipitation during the spring and fall seasons leads to more variability in terms of the best copulas during these two seasons.

In this section, an application showing the effect of ignoring the dependence between temperature and precipitation on the estimation of risks of extreme events such as wet/cool in the winter and dry/hot in the summer is presented. Figure 7 shows the differences between likelihoods of concurrent extremes computed by assuming $P$ and $T$ as dependent and independent variables. We found that generally the differences are positive (varying between 8 and $14 \%$ ), which means that ignoring the dependence leads to underestimating the probabilities of occurrence of wet/cool and dry/hot events up to $14 \%$ in southern Ontario. Also, we observed that likelihood of differences is larger in the case of wet/cool event compared to that in the case of dry/hot event. This can be explained by the fact that precipitation and temperature are more correlated in the winter than in the summer for this region. In particular, the differences are more significant in the urban centers close to the Lake Ontario. In conclusion, this analysis indicates that the correlations between $P$ and $T$ have a direct effect on the estimation of occurrence risk of concurrent climate events.
Another example of the usefulness of modelling the risk of an extreme event based on the joint distribution of temperature and precipitation, as opposed to basing the model on these two variables separately, is shown in Figure 8. In fact, this figure shows the temperatureprecipitation space of grid 1682 (i.e., Toronto area) for the four seasons. The contours represent the bivariate quantile curve for different, simultaneous, nonexceedance events. Note that the quantile function expresses the magnitude of the event in terms of its exceedance or nonexceedance probability, which is also related to the return periods. The quantile curve is composed of two parts: the naïve part (tail) and the proper part (central). The naïve part is composed of two segments starting at the end of both extremities of the proper part. Detailed description and proprieties of the bivariate quantile function can be found in Chebana and Ouarda [77]. For the grid 1682 example in winter, for risk value of $p=0.9$, the univariate quantile values of precipitation and temperature are $10 \mathrm{~mm}$ and $5^{\circ} \mathrm{C}$, respectively. The violet-colored curve in Figure 8 represents the bivariate quantile extracted from the joint distribution. Note that the combination of the univariate values (precipitation $=10 \mathrm{~mm}$ and temperature $=5^{\circ} \mathrm{C}$ ) does not belong to the bivariate quantile curve. This combination corresponds to another risk $(p)$ smaller than the actual risk of $p=0.9$. Therefore, the wrong conclusion (in terms of magnitude and return period) could be made without taking into consideration the joint or confounding distribution. The generality of the bivariate quantile function, which can give several possible scenarios related to the same risk $p$, is not the case of univariate quantile. The univariate quantile represents the extreme points of the proper part of the bivariate quantile curve indicated as the black-dashed line in Figure 8. 

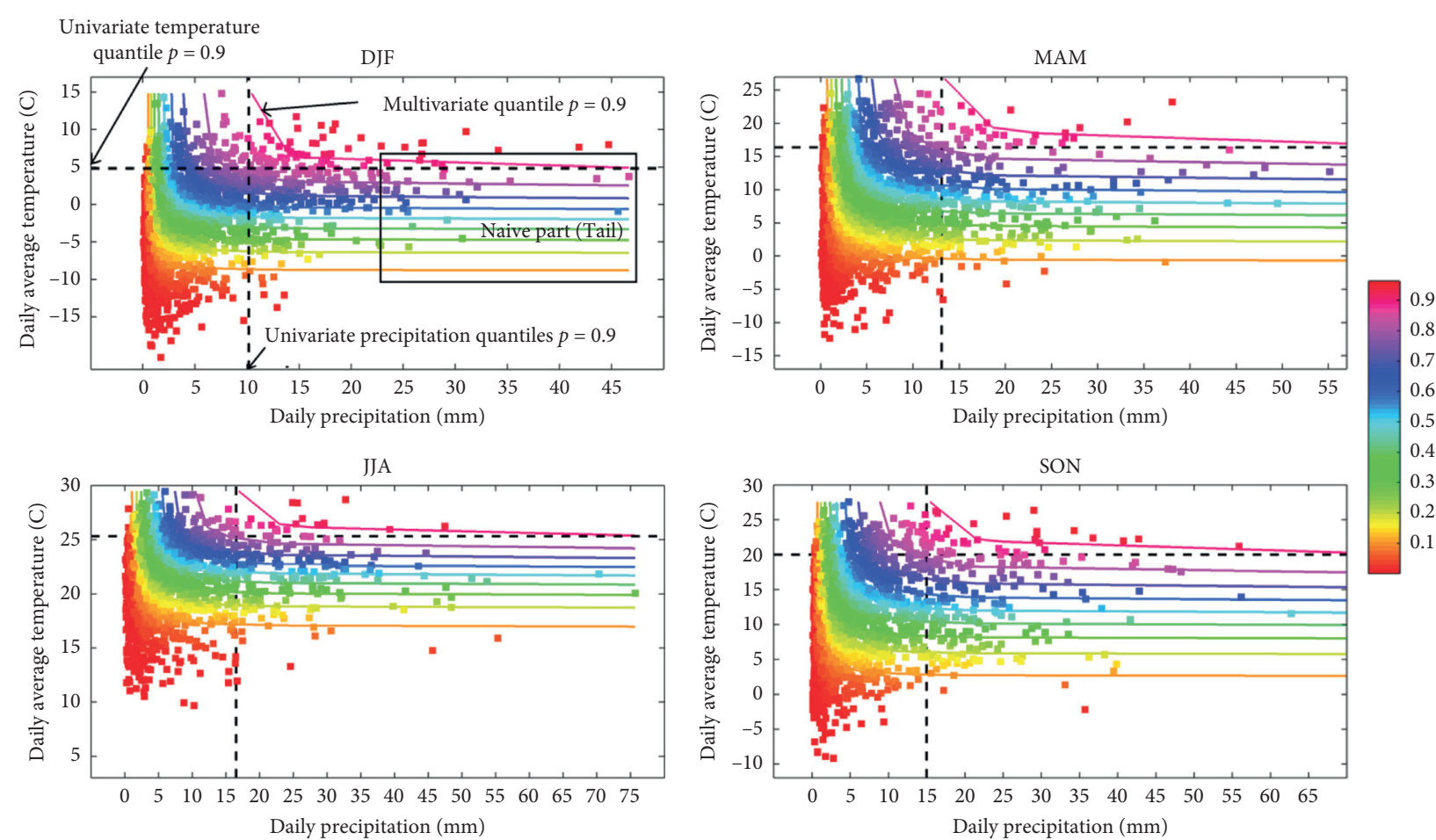

Figure 8: Illustration of the cumulative joint probability $(p)$ for grid 1682. Contours represent the bivariate quantile curve for different nonexceedance events. Univariate quantile can be deduced as extreme value from the bivariate quantile curve (see black-dashed line).

\section{Discussion}

In this study, a copula-based approach was used to determine the inherent seasonal relationship between the average temperature and the total, nonzero precipitation at daily resolution across southern Ontario. We found a positive correlation between temperature and precipitation in the entire region. Our analytical results are consistent with previous studies reported in the literature, which indicate a positive correlation between precipitation and temperature in this region (e.g., $[21,78]$ ) but with a different conclusion as in the work of Trenberth and Shea [28] in which they combine all "warmer" months from May to September. Isaac and Stuart [21] computed a temperature-precipitation index that derives the percentage of precipitation based on temperatures colder than median daily temperature for 51 Canadian meteorological stations. They report a positive correlation during winter for all stations located in southern Ontario and Quebec.

The results of this study are an important step forward to characterize and quantify nonlinear dependence between precipitation and temperature in an area that is prone to the occurrence of extreme weather events and has profound social and economic significance for Canada. The proposed approach demonstrated here is flexible and assumption-free. In fact, the modelled dependence structure does not require the normality of marginal distributions of variables which provide flexibility in correlating variables and also prevents the necessity of similar marginal distributions.
We found that the Gumbel and Clayton copulas are the most suitable to fit the dependence between temperature and precipitation during winter and summer, respectively. Gumbel and Clayton are two asymmetric copulas, with right (Gumbel) and left (Clayton) tail dependence [79]. This explains the significant correlation between extreme temperature and extreme precipitation in this region during these seasons. Mechanistically, this reveals that less precipitation falls in general during cold weather conditions in winter, and more precipitation falls during warm weather in fall. Asymmetric copulas perform better to identify nonlinear correlation between temperature and precipitation in this region.

\section{Conclusion}

In this paper, a copula-based approach was presented to model the seasonal joint or confounding distribution of temperature and precipitation. The proposed approach is flexible and free of assumptions. Five copula members belonging to three families were fitted to 1699 grids $(\sim 10 \mathrm{~km} \times 10 \mathrm{~km}$ resolution $)$ in southern Ontario. For each grid, an information criterion was computed using empirical and theoretical copulas and the best fit copula was selected based on the strength of nonlinear correlations. Modelling of the joint distribution of precipitation and temperature will help to produce improved simulations of weather events which may help to increase the accuracy of risk evaluations.

Results showed that no copula performed consistently as the best copula for all four seasons and for the entire region. 
Gumbel performed as the best fit copula for winter and Clayton copula performed as the best fit copula for summer. More variability in terms of best copula was found in spring and fall, which may be due to the variation in temperature during specific events or thresholds (i.e., around $0^{\circ} \mathrm{C}$ ) between grid points and mixing of precipitation types which can lead to different links with temperature (as noted in [28]). By extracting the multivariate and the univariate quantiles related to a preselected risk, it was found that ignoring the joint or confounding/combined distribution of precipitation and temperature may lead to underestimation of the risk of an extreme event. This underestimation may lead to a misinterpretation and a wrong conclusion in terms of return periods. Our study also reveals that the relationships and physics of combined occurrence of precipitation and temperature events should be taken into account in interpreting climate changes and in climate risk analyses.

Extremes in meteorological variables may have a significant impact on ecosystems and society through the occurrence of extreme weather events. Evaluating the risk potential of climate variable extremes is critical for resilience policy and mitigation of the negative effects of climatic change. A potentially valuable extension of this research is trivariate copula analyses to connect precipitation and temperature with crop production planning and agricultural economics and flood evaluation. Such study could be used in developing risk reduction strategies for farmers and decision-makers, which will become increasingly important in the face of climate change and its associated modification in extremes, water cycle, and hydrometeorological hazards.

\section{Data Availability}

The daily CanGrid data used in this study are obtained from the following website: ftp://ftp.nrcan.gc.ca/pub/outgoing/ canada_daily_grids.

\section{Conflicts of Interest}

The authors declare that they have no conflicts of interest.

\section{Acknowledgments}

Financial support for this study was provided by the Natural Sciences and Engineering Research Council (NSERC) of Canada through the FloodNet Project. The authors also thank researchers at the Natural Resources Canada and Environment and Climate Change Canada for their contribution in providing climate datasets.

\section{References}

[1] D. R. Easterling, G. A. Meehl, C. Parmesan, S. A. Changnon, T. R. Karl, and L. O. Mearns, "Climate extremes: observations, modeling, and impacts," Science, vol. 289, no. 5487, pp. 2068-2074, 2000.

[2] K. E. Kunkel, K. Andsager, and D. R. Easterling, "Long-term trends in extreme precipitation events over the conterminous United States and Canada," Journal of Climate, vol. 12, no. 8, pp. 2515-2527, 1999.
[3] A. J. Lawrence, R. E. Woodruff, and S. Hales, "Climate change and human health: present and future risks," The Lancet, vol. 367, no. 9513, pp. 859-869, 2006.

[4] IPCC, Managing the Risks of Extreme Events and Disasters to Advance Climate Change Adaptation: Special Report of the Intergovernmental Panel on Climate Change, Cambridge University Press, Cambridge, UK, 2013.

[5] D. Hartmann and Coauthors, "Observations: atmosphere and surface," in Climate Change 2013: The Physical Science BasisContribution of Working GroupI to the Fifth Assessment Report of the Intergovernmental Panel on Climate Change, Cambridge University Press, Cambridge, UK and New York, NY, USA, 2013.

[6] G. Flato and Coauthors, "Evaluation of climate models," in Climate Change 2013: The Physical Science Basis, Contribution of Working Group I to the Fifth Assessment Report of the Intergovernmental Panel on Climate Change, vol. 5, pp. 741-866, Cambridge University Press, Cambridge, UK and New York, NY, USA, 2013.

[7] N. Estrella and A. Menzel, "Recent and future climate extremes arising from changes to the bivariate distribution of temperature and precipitation in Bavaria, Germany," International Journal of Climatology, vol. 33, no. 7, pp. 1687-1695, 2013.

[8] B. R. Bonsal, R. Aider, P. Gachon, and S. Lapp, "An assessment of Canadian prairie drought: past, present, and future," Climate Dynamics, vol. 41, no. 2, pp. 501-516, 2013.

[9] A. AghaKouchak, L. Cheng, O. Mazdiyasni, and A. Farahmand, "Global warming and changes in risk of concurrent climate extremes: insights from the $2014 \mathrm{Cal}-$ ifornia drought," Geophysical Research Letters, vol. 41, no. 24, pp. 8847-8852, 2014.

[10] C. M. Little, R. M. Horton, R. E. Kopp, M. Oppenheimer, G. A. Vecchi, and G. Villarini, "Joint projections of US East coast sea level and storm surge," Nature Climate Change, vol. 5, no. 12, p. 1114, 2015.

[11] R.-G. Cong and M. Brady, "The interdependence between rainfall and temperature: copula analyses," The Scientific World Journal, vol. 2012, Article ID 405675, 11 pages, 2012.

[12] J. Huang and H. M. van den Dool, "Monthly precipitationtemperature relations and temperature prediction over the United States," Journal of Climate, vol. 6, no. 6, pp. 1111-1132, 1993.

[13] M. K. Van Aalst, "The impacts of climate change on the risk of natural disasters," Disasters, vol. 30, no. 1, pp. 5-18, 2006.

[14] J. Rockström, M. Falkenmark, L. Karlberg, H. Hoff, S. Rost, and D. Gerten, "Future water availability for global food production: the potential of green water for increasing resilience to global change," Water Resources Research, vol. 45, no. 7, 2009.

[15] H. Ye, E. J. Fetzer, S. Wong et al., "Impact of increased water vapor on precipitation efficiency over northern Eurasia," Geophysical Research Letters, vol. 41, no. 8, pp. 2941-2947, 2014.

[16] R. D. Brown, "Northern hemisphere snow cover variability and change, 1915-97," Journal of Climate, vol. 13, no. 13, pp. 2339-2355, 2000.

[17] D. G. Vaughan and Coauthors, "Observations: cryosphere," in Climate Change, 2013: The Physical Science Basis, Contribution of Working Group I to the Fifth Assessment Report of the Intergovernmental Panel on Climate Change, pp. 317-382, Cambridge University Press, Cambridge, UK and New York, NY, USA, 2013. 
[18] C. Saad, A. St-Hilaire, and P. Gachon, S. El Adlouni, "The 2011 flood event in the Richelieu river basin: causes, assessment and damages," Canadian Water Resources Journal/Revue canadienne des ressources hydriques, vol. 40, no. 1-2, pp. 129-138, 2016.

[19] A. Garcia-Aristizabal, E. Bucchignani, E. Palazzi, D. D'Onofrio, P. Gasparini, and W. Marzocchi, "Analysis of non-stationary climate-related extreme events considering climate change scenarios: an application for multi-hazard assessment in the Dar es Salaam region, Tanzania," Natural Hazards, vol. 75, no. 1, pp. 289-320, 2015.

[20] V. Mishra, J. M. Wallace, and D. P. Lettenmaier, "Relationship between hourly extreme precipitation and local air temperature in the United States," Geophysical Research Letters, vol. 39, 2012.

[21] G. A. Isaac and R. A. Stuart, "Temperature-precipitation relationships for Canadian stations," Journal of Climate, vol. 5, no. 8, pp. 822-830, 1992.

[22] R. W. Portmann, S. Solomon, and G. C. Hegerl, "Spatial and seasonal patterns in climate change, temperatures, and precipitation across the United States," Proceedings of the National Academy of Sciences, vol. 106, no. 18, pp. 7324-7329, 2009.

[23] A. Yatagai and T. Yasunari, "Trends and decadal-scale fluctuations of surface air temperature and precipitation over China and Mongolia during the recent 40 year period (19511990)," Journal of the Meteorological Society of Japan. Ser. Ii, vol. 72, no. 6, pp. 937-957, 1994.

[24] W. Zhao and M. A. K. Khalil, "The relationship between precipitation and temperature over the contiguous United States," Journal of Climate, vol. 6, no. 6, pp. 1232-1236, 1993.

[25] T. C. Johns, J.-F. Royer, I. Hoschel et al., "Climate change under aggressive mitigation: the ENSEMBLES multi-model experiment," Climate Dynamics, vol. 37, no. 9-10, pp. 1975-2003, 2011.

[26] J. Caesar and J. A. Lowe, "Comparing the impacts of mitigation versus non-intervention scenarios on future temperature and precipitation extremes in the HadGEM2 climate model," Journal of Geophysical Research: Atmospheres, vol. 117, no. D15, 2012.

[27] A. Dai, K. E. Trenberth, and T. R. Karl, "Effects of clouds, soil moisture, precipitation, and water vapor on diurnal temperature range," Journal of Climate, vol. 12, no. 8, pp. 2451-2473, 1999.

[28] K. E. Trenberth and D. J. Shea, "Relationships between precipitation and surface temperature," Geophysical Research Letters, vol. 32, no. 14, p. L14703, 2005.

[29] N. Zhao and W. T. Lin, "A copula entropy approach to correlation measurement at the country level," Applied Mathematics and Computation, vol. 218, no. 2, pp. 628-642, 2011.

[30] C. Ohlwein and P. Friederichs, "Multivariate non-normally distributed random variables in climate researchintroduction to the copula approach," Nonlinear Processes in Geophysics, vol. 15, no. 5, pp. 761-772, 2008.

[31] E. Paixao, H. Auld, M. M. Q. Mirza, J. Klaassen, and M. W. Shephard, "Regionalization of heavy rainfall to improve climatic design values for infrastructure: case study in Southern Ontario, Canada," Hydrological Sciences Journal, vol. 56, no. 7, pp. 1067-1089, 2011.

[32] M. A. Estoque, "Further studies of a lake breeze part I: observational study," Monthly Weather Review, vol. 109, no. 3, pp. 611-618, 1981.
[33] M. A. Estoque and J. M. Gross, "Further studies of a lake breeze part II: theoretical study," Monthly Weather Review, vol. 109, no. 3, pp. 619-634, 1981.

[34] D. W. McKenney, M. F. Hutchinson, P. Papadopol et al., "Customized spatial climate models for North America," Bulletin of the American Meteorological Society, vol. 92, no. 12, pp. 1611-1622, 2011.

[35] M. F. Hutchinson, ANUSPLIN Version 4.3, Australian National University, Canberra, UK, 2004.

[36] A. J. Cannon, S. R. Sobie, and T. Q. Murdock, "Bias correction of GCM precipitation by quantile mapping: how well do methods preserve changes in quantiles and extremes?" Journal of Climate, vol. 28, no. 17, pp. 6938-6959, 2015.

[37] E. P. Diaconescu, P. Gachon, and R. Laprise, J. F. Scinocca, "Evaluation of precipitation indices over North America from various configurations of regional climate models," Atmosphere-Ocean, vol. 54, no. 4, pp. 418-439, 2016.

[38] H. I. Eum and P. Gachon, R. Laprise, "Developing a likely climate scenario from multiple regional climate model simulations with an optimal weighting factor," Climate Dynamics, vol. 43, no. 1-2, pp. 11-35, 2014.

[39] H.-I. Eum, P. Gachon, and R. Laprise, T. Ouarda, "Evaluation of regional climate model simulations versus gridded observed and regional reanalysis products using a combined weighting scheme," Climate Dynamics, vol. 38, no. 7-8, pp. 1433-1457, 2012.

[40] R. F. Hopkinson, D. W. McKenney, E. J. Milewska, M. F. Hutchinson, P. Papadopol, and L. A. Vincent, "Impact of aligning climatological day on gridding daily maximumminimum temperature and precipitation over Canada," Journal of Applied Meteorology and Climatology, vol. 50, no. 8, pp. 1654-1665, 2011.

[41] G. Salvadori, C. De Michele, N. Kottegoda, and R. Rosso, "Extremes in Nature: An Approach Using Copulas," Water Science and Technology Library, Vol. 56, Springer, Dordrecht, Netherlands, 2007.

[42] F. Serinaldi, "A multisite daily rainfall generator driven by bivariate copula-based mixed distributions," Journal of Geophysical Research, vol. 114, no. D10, p. 103, 2009.

[43] C. De Michele and G. Salvadori, "A generalized pareto intensity-duration model of storm rainfall exploiting 2-copulas," Journal of Geophysical Research, vol. 108, no. D2, 2003.

[44] Z. Hao and A. AghaKouchak, "Multivariate standardized drought index: a parametric multi-index model," Advances in Water Resources, vol. 57, pp. 12-18, 2013.

[45] T. Lee, R. Modarres, and T. B. M. J. Ouarda, "Data-based analysis of bivariate copula tail dependence for drought duration and severity," Hydrological Processes, vol. 27, no. 10, pp. 1454-1463, 2013.

[46] B. Renard and M. Lang, "Use of a Gaussian copula for multivariate extreme value analysis: some case studies in hydrology," Advances in Water Resources, vol. 30, no. 4, pp. 897-912, 2007.

[47] S. Grimaldi and F. Serinaldi, "Asymmetric copula in multivariate flood frequency analysis," Advances in Water Resources, vol. 29, no. 8, pp. 1155-1167, 2006.

[48] F. Chebana and T. B. M. J. Ouarda, "Multivariate L-moment homogeneity test," Water Resources Research, vol. 43, no. 8, p. W08406, 2007.

[49] F. Chebana and T. B. M. J. Ouarda, "Index flood-based multivariate regional frequency analysis," Water Resources Research, vol. 45, no. 10, p. W10435, 2009.

[50] M. Leonard, A. Metcalfe, and M. Lambert, "Frequency analysis of rainfall and streamflow extremes accounting for 
seasonal and climatic partitions," Journal of Hydrology, vol. 348, no. 1-2, pp. 135-147, 2008.

[51] S. E. Adlouni and T. B. M. J. Ouarda, "Comparaison des méthodes d'estimation des paramètres du modèle GEV non stationnaire," Revue des sciences de l'eau, vol. 21, no. 1, pp. 35-50, 2008.

[52] Rosa and F. Leite, "Statistical Modeling of Flood Dischargesand Volumes in Continental Portugal: Convencional and Bivari-Ate Analyses," Extended Abstract. Dissertation for Obtaining the Degree of Master in Civil Engineering, Universidade Técnica deLisboa, Lisbon, Portugal, 2011.

[53] M. Salarpour, Z. Yusop, F. Yusof, S. Shahid, and M. Jajarmizadeh, "Flood frequency analysis based on t-copula for Johar river, Malaysia,” Journal of Applied Sciences, vol. 13, no. 7, pp. 1021-1028, 2013.

[54] N. Bezak, M. Mikoš, and M. Šraj, "Trivariate frequency analyses of peak discharge, hydrograph volume and suspended sediment concentration data using copulas," Water Resources Management, vol. 28, no. 8, pp. 2195-2212, 2014.

[55] C. De Michele, G. Salvadori, M. Canossi, A. Petaccia, and R. Rosso, "Bivariate statistical approach to check adequacy of dam spillway," Journal of Hydrologic Engineering, vol. 10, no. 1, pp. 50-57, 2005.

[56] L. Zhang and V. P. Singh, "Bivariate rainfall frequency distributions using archimedean copulas," Journal of Hydrology, vol. 332, no. 1-2, pp. 93-109, 2006.

[57] A. AghaKouchak, "Entropy-copula in hydrology and climatology," Journal of Hydrometeorology, vol. 15, no. 6, pp. 2176-2189, 2014.

[58] A. Sklar, "Random variables, joint distribution functions, and copulas," Kybernetika, vol. 9, no. 449, 460 pages, 1973.

[59] R. B. Nelsen, "Dependence and order in families of archimedean copulas," Journal of Multivariate Analysis, vol. 60, no. 1, pp. 111-122, 1997.

[60] G. Frahm, M. Junker, and A. Szimayer, "Elliptical copulas: applicability and limitations," Statistics \& Probability Letters, vol. 63 , no. 3, pp. 275-286, 2003.

[61] A. Bárdossy, "Copula-based geostatistical models for groundwater quality parameters," Water Resources Research, vol. 42 , no. $11,2006$.

[62] B. Gräler, M. J. van den Berg, S. Vandenberghe et al., "Multivariate return periods in hydrology: a critical and practical review focusing on synthetic design hydrograph estimation," Hydrology and Earth System Sciences, vol. 17, no. 4, pp. 1281-1296, 2013.

[63] G. Salvadori and C. D. Michele, "Frequency analysis via copulas: theoretical aspects and applications to hydrological events," Water Resources Research, vol. 40, no. 12, 2004.

[64] A. Min and C. Czado, "Bayesian inference for multivariate copulas using pair-copula constructions," Journal of Financial Econometrics, vol. 8, no. 4, pp. 511-546, 2010.

[65] E. Parent, A.-C. Favre, J. Bernier, and L. Perreault, "Copula models for frequency analysis what can be learned from a Bayesian perspective?" Advances in Water Resources, vol. 63, pp. 91-103, 2014.

[66] B. Brahimi, F. Chebana, and A. Necir, "Copula representation of bivariate L-moments: a new estimation method for multiparameter two-dimensional copula models," Statistics, vol. 49, no. 3, pp. 497-521, 2015.

[67] S. A. Huebener and R. Parsa, "Fitting bivariate loss distributions with copulas," Insurance: Mathematics and Economics, vol. 24, no. 1-2, pp. 139-148, 1999.
[68] S.-C. Kao and R. S. Govindaraju, "Trivariate statistical analysis of extreme rainfall events via Plackett family of copulas,", Water Resources Research, vol. 44, no. 2, p. W02415, 2008.

[69] E. Schwarz Gideon, "Estimating the dimension of a model," Annals of Statistics, vol. 6, no. 2, pp. 461-464, 1978.

[70] R. T. Clarke, "Fitting Distributions," Chapter 4 Statistical Modeling in Hydrology, pp. 39-85, John Wiley \& Sons Ltd, Chichester, UK, 1994.

[71] NERC, Flood Studies Report (In Five Volumes), Natural Environment Research Council, London, UK, 1975.

[72] F. Chebana, S. E. Adlouni, and B. Bobée, "Mixed estimation methods for Halphen distributions with applications in extreme hydrologic events," Stochastic Environmental Research and Risk Assessment, vol. 24, no. 3, pp. 359-376, 2010.

[73] J. R. M. Hosking, "L-moments: analysis and estimation of distributions using linear combinations of order statistics," Journal of the Royal Statistical Society, vol. 52, no. 2, pp. 105-124, 1990.

[74] A. R. Rao and K. H. Hamed, Flood Frequency Analysis, CRC Press, Boca Raton, FL, 2000.

[75] P. Zhou and Z. Liu, "Likelihood of concurrent climate extremes and variations over China," Environmental Research Letters, vol. 13, no. 9, Article ID 094023, 2018.

[76] J. R. Westmacott and D. H. Burn, "Climate change effects on the hydrologic regime within the Churchill-Nelson river basin," Journal of Hydrology, vol. 202, no. 1-4, pp. 263-279, 1997.

[77] F. Chebana and T. B. M. J. Ouarda, "Multivariate quantiles in hydrological frequency analysis," Environmetrics, vol. 22, no. 1, pp. $63-78,2011$.

[78] R. A. Madden and J. Williams, "The correlation between temperature and precipitation in the United States and Europe," Monthly Weather Review, vol. 106, no. 1, pp. $142-147,1978$.

[79] G. G. Venter, "Tails of copulas," in Proceedings of the Casualty Actuarial Society, vol. 89, no. 171, pp. 68-113, Philadelphia, 2002 March. 